\title{
Neurobiological Bases of Learning and Their Role for the Paradigm Shift in Education
}

\author{
Viviana Chavez-Mancilla ${ }^{1}$, Jorge Parodi ${ }^{2}$ \\ ${ }^{1}$ Laboratorio de Investigación y Educación, Tonalli Ltda, Temuco, Chile \\ ${ }^{2}$ Laboratorio de Fisiología de la Reproducción, Escuela de Medicina Veterinaria, Núcleo de Investigación en \\ Producción Alimentaria (NIPA), Facultad de Recursos Naturales, Universidad Católica de Temuco, Temuco, \\ Chile \\ Email: jparodi@uct.cl
}

Received 18 August 2015; accepted 23 October 2015; published 26 October 2015

Copyright (C) 2015 by authors and Scientific Research Publishing Inc.

This work is licensed under the Creative Commons Attribution International License (CC BY).

http://creativecommons.org/licenses/by/4.0/

(c) (i) Open Access

\begin{abstract}
In recent years, neurobiology has produced the cellular foundations that account for the phenomena of memory and learning in mammals. Nevertheless, this information has not always been applied to educational processes. Our paper reviews the information regarding the cellular processes underlying learning and how these may impact or explain didactic processes, forcing us to rethink current paradigms.
\end{abstract}

Keywords

Metaplasticity, Neuron, Learning, Teaching

\section{Introduction}

In the course of his or her duties, the professor routinely faces a series of problems and challenges with the aim of effecting true learning on the part of his students. For this reason, it is common to hear professors of varying educational levels say, "There are serious problems with learning among the students," "the students are not capable of learning," "what must I do for my students to learn," "the students refuse to learn” despite all the efforts made to identify the best strategy to captivate students so that they might achieve real learning. The above leads us to reflect on learning. Upon realizing a search to define learning, we encountered two main currents of thought, one relating to the fields of psychology and sociology, which understood learning as a change in conduct of a permanent nature in a student, especially associated to environmental stimuli. It is precisely this vision that one begins to internalize and use, beginning with entry into the pedagogical field-leaving aside, and even behind permanently, the biological elements that influence learning. 
It is precisely this second, biological viewpoint through which neuroscientists seek to understand the processes that lead to these changes in students and can allow the explanation of why, on many occasions, the desired results are unable to be achieved, despite the methodological efforts made by the teacher.

We proposed a review exploring a basic concept of neurobiology and the relation described with the education. We focus the present work for having more discussion of the cells model and the child complex education process and in the future, working more close both discipline.

\subsection{The Contribution of Neurobiology: Synapses and Their Function}

The formation of synaptic connections involves the activation of receptors in response to extracellular signals that modulate different processes such as the reorganization of the actin cytoskeleton and the recruitment of specific pre and post-synaptic proteins. Despite the existence of many molecular mechanisms involved in synaptic differentiation, some of which have been extensively characterized, the signaling pathways that regulate synaptic structuring have yet to be completely described. In recent decades, ligands have been described as being capable of participating in these processes, although it is still not adequately understood how its effect is mediated.

The synapse is what functionally connects neurons to each other or to other types of cells and is a limited and specialized region where intercellular communication is produced. A typical neuron has thousands of intercellular connections, called synapses. The majority of the synapses make contact between the axon of the dendrites, but other types of connections also take place, including in the axon cell body, axon to axon and dendrite to dendrite (Ventura \& Harris, 1999). Synapses are too small to be recognizable under a traditional or field microscope. Their structure and location can be observed using an electron microscope, and their function can be deduced based on the structure. In chemical synapses, information transmission is achieved in a conventional directional manner. In this way, a presynaptic cell transmits information to the postsynaptic cell. This can generate remodeling of its structure and function. Although we realize that this is a spatial definition, and the most difficult component to define continues to be the synapse, the glial cell has been incorporated as a key synaptic element in recent years. The presynaptic terminal is a specialized area that contains neurotransmitters enclosed in tiny spheres called synaptic vesicle membranes. This element regulates exocytosis mechanisms shared with other cellular models (Rosenmund \& Stevens, 1996). A group of synaptic vesicles called the readily releasable pool (RRP) are coupled to the plasmatic membrane in the active presynaptic zones thanks to a series of coordinated scaffolding proteins and a system of enzyme complexes that drive the process. Another region of the cell is that contains postsynaptic neurotransmitters is called the postsynaptic density. The proteins in the PSD are important neurotransmitter receptors, anchoring proteins, and intracellular signal translators, as has been mentioned. Many synaptic plasticity studies focus on the structural changes in this region and the modulation of the activity of these receptors. The receptors and PSD are located in specialized protuberances called dendritic spines. In the peripheral zone of the spines there are a series of protein elements that permit the coordination of anchoring and synaptic transmission in the central neurons. This permits intercellular communication and the generation of cognitive processes such as learning and memory (El-Husseini, Schnell, Chetkovich, Nicoll, \& Bredt, 2000).

Long ago, the study of synaptic plasticity contributed to the understanding of the physiological process allowing the system to generate information input and retain the information is distinct areas of the brain. Specifically in the hippocampus, one of the zones with the most information acquisition, synaptic plasticity is a form of modification of the electrical activity and structure of synaptic transmission, such as its strength and efficacy (Citri \& Malenka, 2008; Leuner \& Gould, 2010).

\subsection{Calcium as a Secondary Messenger}

The processes that come to regulate a classic secondary messenger of cellular physiology, such as intracellular calcium, have been studied for many years. This ion is important for regulating the activity of kinase enzymes, phosphates, gene activation, and protein translation. Calcium is required in high concentrations for brief periods of time, and the cell generates various fine mechanisms to regulate its intracellular concentration and maintain a physiological gradient (Hurwitz, 1996; Stewart, 1985). Therefore signals that temporarily increase intracellular calcium are indicative of the activation of cellular processes; however, a sustained increase of the cellular concentration indicates phenomena of cellular toxicity (Pounds, 1984). There are classical phenomena of biological 
importance that show calcium as the mechanism responsible for the liberation of synaptic vesicles, able to change in a span of milliseconds from base concentrations of free calcium from $100 \mathrm{nM}$ to concentrations in the range of $\mu \mathrm{M}$ after depolarizing the presynaptic terminal (Elhamdani, Palfrey, \& Artalejo, 2001). These changes in the calcium concentration can vary according to the cell type and the type of stimulation. In addition, they can be correlated to the process of vesicular exocytosis by observing different techniques for measuring calcium currents, cellular capacitance (Trifaro, Rose, Lejen, \& Elzagallaai, 2000), fluorometric calcium measurement, and amperometric registration (Elhamdani, Bossu, \& Feltz, 1994). This normal process of vesicle liberation is highly dependent on calcium influx. In addition, it is key to the propagation of nerve impulse and the establishment of neuronal connections that explain the cognitive functions of the brain.

\subsection{Signalling through G Protein Coupled Receptors}

Heterotrimeric $\mathrm{G}$ proteins are located on the intracelular section of the plasmatic membrane, to which they are bound by their $\alpha$ and $\beta \gamma$ subunits with fatty acid or isoprenoid hydrophobic structures (Tilakaratne \& Sexton, 2005). At rest, the $\alpha$ subunit is bound to Guanosine diphosphate (GDP), and this increases the affinity for the $\beta \gamma$ subunits. The three subunits are located in the cellular membrane, and when a $G$ protein coupled receptor (GPCR) receives a stimulus and activates the G protein, the GDP is replaced by the GTP; this prompts a change in the $\alpha$ subunit, and the affinity for the $\beta \gamma$ subunit is diminished, separating the trimer (Hess, Roper, Grill, \& Koelle, 2004; Yi, Kitano, \& Simon, 2003). The $\alpha$ subunit increases its enzymatic activity. With this, the GTP is hydrolyzed, producing the end of the cycle and returning to the rest condition (Warner \& Weinstein, 1999). The trimeric complex breaks into two parts: one, $\beta \gamma$, that can perform biological functions with the opening of channels; the other, $\alpha$, that activates a cellular signaling cascade, such as through adenylate cyclase and cyclic Adenosine monophosphate (AMP) generation (Olate \& Allende, 1991; Shichida \& Morizumi, 2007). Thus, GTPase activity is crucial to G protein function. The $\alpha$ subunit that places the mentioned hydrolytic activity is also modulated through accessory proteins, as they belong to the following groups:

1) GEF, guanine nucleotide factor, is a protein factor that facilitates the exchange of GDP from the G protein structure for Guanosine triphosphate (GTP), which activates the G protein.

2) GAP, GTPase-activating proteins, which favour the rupture of the phosphodiester bond. This converts GTP to GDP, which inactivates the G protein.

These regulators, sometimes referred to as RGS in the literature (Regulator of G protein Signaling) (Burns \& Wensel, 2003; Cho, Harrison, \& Kehrl, 2004), modify the hydrolytic activity of G proteins through molecular mechanisms that have been described in certain cases such as development, modulation against aggressive stimuli, physiopathology of some diseases, and others. It is noteworthy that GAP only increases the velocity of GTPase activity; the key to the regulation mediated by G proteins consists of a GTPase activity that provides a short and definite activity lapse, since overstimulation generates hyperactivity and can lead to pathological situations such as cancer or dehydration, similar to the toxic effect of the cholera toxin (Jean-Baptiste, Yang, \& Greenwood, 2006).

\subsection{Synaptic Metaplasticity}

This process occurs during cerebral development and adult stages and is one of the current hypotheses that could explain memory and learning. Beginning with Hebb and Cajal's postulations, communications and modifications in the synapse have been intensely studied, and today the understanding of this subject has been advanced in various sub-areas within the field. How does the hippocampus function in memory? The role of the hippocampus in memory has been studied in rodents, primarily in rats, and suggests that this structure generates a neuronal representation of space called the cognitive map (O'Keefe \& Nadel, 1978). This model is based on the discovery of certain cells in the hippocampus called place cells. These cells change their discharge frequency according to the position and orientation of the animal and return to their previous frequency when the animal assumes its original position (O'Keefe \& Dostrovsky, 1971). This process suggests that spacial information is coded into the electrical activity of the hippocampal cells and that changes in the homeostasis of the hippocampus would affect the function of these cells, including their function in memory (Morris, Garrud, Rawlins, \& O’Keefe, 1982; O’Keefe \& Dostrovsky, 1971; Sutherland, Kolb, \& Whishaw, 1982).

The possible contribution of synaptic plasticity in learning and memory is exemplified in a variety of types of 
long term plasticity. The majority of the areas studied within the hippocampus are located in CA1, and the different types of protocols involved indicate the complexity of explaining the processes that occur in Long term potentiation (LTP) and long term depression (LTD).

\subsection{Long Term Potentiation and Long Term Depression}

LTP in CA1 of the hippocampus is one of the most interesting processes to study electrophysiologically, as it codifies information acquisition during learning of the zone or place related to long term memory (Martin, Grimwood, \& Morris, 2000; Whitlock, Heynen, Shuler, \& Bear, 2006). This process occurs in the synaptic cleft when the pre and post-synaptic regions interact, as well as with glial modulations (Paixao \& Klein, 2010). In addition, it will depend on the anatomic region and the way it is modulated by various neurotransmitters, neurotrophic factors (Bramham and Messaoudi 2005; Poo, 2001), and certain medications (Ron \& Jurd, 2005). One of the most studied types of LTP in the hippocampus, and specifically in CA1, is dependent on N-metil-D-aspartate receptor (NMDAR). Activation depends on a strong post-synaptic depolarizing wave induced by the release of glutamate, permitting AMPAR activation that induces unblocking of the NMDAR. This generates of LTP induction, facilitating the influx of calcium to the dendritic spine and the activation of different protein kinases such as CaMKII (Wayman, Lee, Tokumitsu, Silva, \& Soderling, 2008). There are many protocols for inducing LTP in hippocampal clefts; among them are High Frequency Stimulation (HFS) and Theta Burst Stimulation (TBS), since the objective is to experimentally imitate the phenomenon of a strong depolarization that permits NMDAR activation and generate a LTP (Raymond, 2007). Other types of protocols, such as Spike Time Dependent Plasticity (STDP), can be used for generating LTP in neurons that are in contact, as in a culture (Dan \& Poo, 2006). In addition, there are chemical modulators of LTP, such as forskolin and Brain-derived neurotrophic factor (BDNF) (Kovalchuk, Hanse, Kafitz, \& Konnerth, 2002; Otmakhov et al., 2004), which replicate a similar mechanism that induces depolarization. Other types of LTP are those that are independent of NMDAR. These are most studied in the place of the mossy fiber of the hippocampus (Bortolotto, Lauri, Isaac, \& Collingridge, 2003). In these cases, the induction of LTP is dependent on the metabotropic glutamine receptors (mGluR).

\subsection{Long Term Depression (LTD)}

However, LTP isn't the only type of long term plasticity that controls the process of interneuronal communication. LTD is another type of plasticity that balances the process of LTP and allows a refinement of the system. Long term depression consists of a process that diminishes the synaptic force that permits a reduction of the afferent neurons' response to stimuli (Collingridge, Peineau, Howland, \& Wang, 2010). The information about this phenomenon has yet to be fully understood, but recent research has had to demonstrate a similarity to the components that shape LTP and LTD. In this case, some type of LTD is dependent on NMDAR in CA1 of the hippocampus, but the difference between LTP and LTD is the calcium concentration, due to the fact that LTD needs a slight increase in calcium (Cummings, Mulkey, Nicoll, \& Malenka, 1996; Malenka \& Bear, 2004). This variation in the calcium concentration can be translated into the temporary increase of cation during activity of the NMDAR ("induction") that permits the directionality of LTP or LTD. The experimental "induction" of LTD depends on the anatomic region and the components of the proteins that form the synaptic cleft; nevertheless, in the CA1 of the hippocampus, the most utilized protocol is for pulse pairing in a repetitive Low Frequency Stimulation (LFS) (Kemp, McQueen, Faulkes, \& Bashir, 2000) that consists of $9001 \mathrm{~Hz}$ stimuli that partially eliminate the magnesium that blocks the NMDAR. This allows a modest depolarization that permits the activation of phosphates such as calcineurin. As with LTP, the chemical inductors present in LTD generate the activation of the muscarinic receptors (mAChRs) using carbachol in the CA1 del hippocampus and regulate these synaptic changes (Jo et al., 2010).

In the last five years, academics have been aware of the importance of neuronal plasticity in learning and it is understood as the creation of new neurons or networks, when it is better associated to the type of structural functional change that can exist in a neuron. From this point of view, the changes on the receptor level are valid in talking about neuronal plasticity. It is only necessary to change the functional state of the protein, through states of phosphorylation states, to understand that there is a metaplasticity associated to learning. This is scalable to more complex processes, such as receptor insertion and removal, new membranes, and new synapses, which can begin with as little as the phosphorylation of an amino acidic residue from a synaptic protein. However, the world of neuroscience has discarded this concept and moved on to metaplastic processes (Abraham \& Bear, 
1996). These involve positive and negative changes in synaptic function, that is to say, the gain or loss of function considered as a whole, making this a remodeling phenomenon and thus learning (Abraham, 1999). Since the studies of facial migration, long term potentiation and depression, and the demonstration of neurogenic niches (Altman, 1969), the paradigm of learning and neuronal remodeling has changed (Bliss, Collingridge, \& Morris, 2014; Neves, Cooke, \& Bliss, 2008). Within Kirkwood's work we can see the importance of a cellular and molecular base for the concept of andragogy, which redefines the way we learn (Boric, Munoz, Gallagher, \& Kirkwood, 2008; Yang et al., 2013). Cellular studies have clearly shown that stimuli that generate changes in conduct are reinforced or replicated in fear or aggression systems, as well as pleasure systems. This shows that we learn from aversion and pleasure systems. The neurobiological evidence supporting this idea is overwhelming, and models of this type have been found since Kandell's work on conditioning in aplysias (Sehgal, Song, Ehlers, \& Moyer, 2013). Primates, and therefore humans, are not exempt from this. The examples in pedagogy are myriad: children are taught to stay away from danger by aversive stimuli, we develop tastes for food from pleasure responses, and we maintain habits and behavior according to early stimuli of one type or another (Kandel, 1978). In studies of evolution and neurobiology, it is classically seen that reward systems allow us to form food habits. The explanation of why the brain likes French fries is a neurological model of conduct and learning (Ziemann \& Siebner, 2008). But is it constant?

It has been suggested that as we age we learn slower and it is difficult to change habits and behaviors, but it is a social construction that adults do not learn well. What is the evidence that supports this? If we discard neurodegenerative pathologies and observe the elderly population, this affirmation does not stand, statistically speaking. We can see that the retirement age in some first world countries exceeds 70 - clearly these individuals must maintain a certain vigor and capability of learning in order to stay active in the workforce. In this case, our premise is poorly formulated and it would be more appropriate be to say that adults learn differently. Do we need to use a new teaching method?

\subsection{Andragogy, Teaching, and Change}

The experimental evidence from Kirkwood's work supports this idea; a brief overview of his work suggests that groups of aged rats, when stimulated in a new paradigm of the induction protocol for LTP or LTD respond even better than young rats (Boric et al., 2008). Basically, using a system of non-repetitive mechanical aversive stimulation improves learning. This is basically learning through reasoning and use of deductive capacities. Should we change didactics? Indeed the experimental evidence indicates that we should explore new teaching strategies. In order to teach adults we must ask ourselves, "When is a brain mature?" What is appropriate educational stimulation? What is environment of reinforcement? (Carrera, 2014).

We must not confuse "adult" with its social definition, which is something between responsible and independent in our society. Here we refer to a mature brain that requires new inputs of stimulation in order to be able to reorganize its synapses and generate habitual changes. We also consider the environment as a key factor in the learning process (Barnes, 1994; Bergado \& Almaguer, 2002).

What are the educational tools for this? This is the future of research. The educational model has not varied much and it is difficult to introduce new methods, but we must evaluate the current methods and the system of problem resolution applied to learning models, as competition could be part of the solution (Saura-Llamas, Saturno Hernández, \& Romero Sánchez, 2006). These require changing the speed of results as well as the metrics used to generate a successful referential database. In this respect, the empirical evidence suggests that in adult education, respecting current abilities and updating them without devaluing what has already been learned is a strategy that works. We must also acknowledge that it is not possible to use a ladder approach or reward system to evaluate the mastery of new knowledge and skills, but rather it is preferable to use an evaluative system focusing on the use of newly acquired abilities (Hubackova \& Semradova, 2014). We must consider a change from the formal approach without passing onto informality. We cannot forget that the great educational revolution is the fruit of the industrial revolution and is born out of the necessity to train the worker for extant tasks; this is our starting point. We have more adults pursuing education, and teaching must update its methods in order to generate new knowledge (Hubackova \& Semradova, 2014).

We cannot fail to mention, however briefly, the Montessori Method and validate its view of environmentsomething that neurobiology has supported (Edwards, 2006). The learning achieved in environments specifically designed to modulate the response of the autonomous system shows better results in evaluations of the acquisi- 
tion and consolidation of new abilities in experimental models. This shows that the educational environment has a neurobiological explanation and that we must maintain this new educational paradigm for a mature brain that requires use of new, important, and regulated stimulating inputs to general structural and functional changes that are translated into learning (Collins, 2007; Edwards, 2006; Garthe, Behr, \& Kempermann, 2009; Spencer, 2008).

\section{Conclusion}

First, we must highlight the complexity of the neurobiological process of the synapse and its metaplasticity, as we have summarized here, including the diverse common actors in the cells such as calcium and proteins. These indicate a complex model at the cellular level. This leads us to rethink the way we learn and the manner in which we are focusing on teaching, both at work and in the classroom. It means realizing a transformation that responds to educational needs where the focus is learning rather than training; the latter implies a repetition of actions in order to acquire abilities without the necessity of thinking or pursuing new strategies for achieving the same goals in a more original way.

\section{Acknowledgements}

Jorge Parodi has MECESUP-UCT grant 0804; Viviana Chávez receives student aid from Tonalli ltd-Masters Grant.

\section{References}

Abraham, W. C. (1999). Metaplasticity: Key Element in Memory and Learning? News in Physiological Sciences, 14, 85. http://www.ncbi.nlm.nih.gov/pubmed/11390826

Abraham, W. C., \& Bear, M. F. (1996). Metaplasticity: The Plasticity of Synaptic Plasticity. Trends in Neurosciences, 19, 126-130. http://www.ncbi.nlm.nih.gov/pubmed/8658594 http://dx.doi.org/10.1016/S0166-2236(96)80018-X

Altman, J. (1969). Autoradiographic and Histological Studies of Postnatal Neurogenesis. Iv. Cell Proliferation and Migration in the Anterior Forebrain, with Special Reference to Persisting Neurogenesis in the Olfactory Bulb. The Journal of Comparative Neurology, 137, 433-457. http://dx.doi.org/10.1002/cne.901370404

Barnes, C. A. (1994). Normal Aging: Regionally Specific Changes in Hippocampal Synaptic Transmission. Trends in Neurosciences, 17, 13-18. http://dx.doi.org/10.1016/0166-2236(94)90029-9

Bergado, J. A., \& Almaguer, W. (2002). Aging and Synaptic Plasticity: A Review. Neural Plasticity, 9, $217-232$. http://dx.doi.org/10.1155/NP.2002.217

Bliss, T. V., Collingridge, G. L., \& Morris, R. G. (2014). Synaptic Plasticity in Health and Disease: Introduction and Overview. Philosophical Transactions of the Royal Society B, 369, Article ID: 20130129. http://dx.doi.org/10.1098/rstb.2013.0129

Boric, K., Munoz, P., Gallagher, M., \& Kirkwood, A. (2008). Potential Adaptive Function for Altered Long-Term Potentiation Mechanisms in Aging Hippocampus. Journal of Neuroscience, 28, 8034-8039. http://dx.doi.org/10.1523/JNEUROSCI.2036-08.2008

Bortolotto, Z. A., Lauri, S., Isaac, J. T., \& Collingridge, G. L. (2003). Kainate Receptors and the Induction of Mossy Fibre Long-Term Potentiation. P Philosophical Transactions of the Royal Society B, 358, 657-666. http://dx.doi.org/10.1098/rstb.2002.1216

Burns, M. E., \& Wensel, T. G. (2003). From Molecules to Behavior: New Clues for Rgs Function in the Striatum. Neuron, 38, 853-856. http://dx.doi.org/10.1016/S0896-6273(03)00361-1

Carrera, R. M. H. (2014). Training in Companies, Permanent Training and Adult Learning: An Epistemological Approach. Procedia-Social and Behavioral Sciences, 139, 434-440. http://dx.doi.org/10.1016/j.sbspro.2014.08.035

Cho, H., Harrison, K., \& Kehrl, J. H. (2004). Regulators of G Protein Signaling: Potential Drug Targets for Controlling Cardiovascular and Immune Function. Current Drug Targets_Immune, Endocrine \& Metabolic Disorders, 4, 107-118. http://www.ncbi.nlm.nih.gov/entrez/query.fcgi?cmd=Retrieve\&db=PubMed\&dopt=Citation\&list_uids=15180451 http://dx.doi.org/10.2174/1568008043339938

Citri, A., \& Malenka, R. C. (2008). Synaptic Plasticity: Multiple Forms, Functions, and Mechanisms. Neuropsychopharmacology, 33, 18-41. http://dx.doi.org/10.1038/sj.npp.1301559

Collingridge, G. L., Peineau, S., Howland, J. G., \& Wang, Y. T. (2010). Long-Term Depression in the CNS. Nature Reviews Neuroscience, 11, 459-473. http://dx.doi.org/10.1038/nrn2867 
Collins, J. W. (2007). The Neuroscience of Learning. Journal of Neuroscience Nursing, 39, 305-310. http://www.ncbi.nlm.nih.gov/entrez/query.fcgi?cmd=Retrieve\&db=PubMed\&dopt=Citation\&list_uids=17966298 http://dx.doi.org/10.1097/01376517-200710000-00008

Cummings, J. A., Mulkey, R. M., Nicoll, R. A., \& Malenka, R. C. (1996). Ca ${ }^{2+}$ Signaling Requirements for Long-Term Depression in the Hippocampus. Neuron, 16, 825-833. http://dx.doi.org/10.1016/S0896-6273(00)80102-6

Dan, Y., \& Poo, M. M. (2006). Spike Timing-Dependent Plasticity: From Synapse to Perception. Physiological Reviews, 86, 1033-1048. http://dx.doi.org/10.1152/physrev.00030.2005

Edwards, C. P. (2006). Montessori Education and Its Scientific Basis. Journal of Applied Developmental Psychology, 27, 183-187. http://dx.doi.org/10.1016/j.appdev.2005.12.012

Elhamdani, A., Bossu, J. L., \& Feltz, A. (1994). Evolution of the $\mathrm{Ca}^{2+}$ Current during Dialysis of Isolated Bovine Chromaffin Cells: Effect of Internal Calcium. Cell Calcium, 16, 357-366. http://dx.doi.org/10.1016/0143-4160(94)90029-9

Elhamdani, A., Palfrey, H. C., \& Artalejo, C. R. (2001). Quantal Size Is Dependent on Stimulation Frequency and Calcium Entry in Calf Chromaffin Cells. Neuron, 31, 819-830. http://dx.doi.org/10.1016/S0896-6273(01)00418-4

El-Husseini, A. E., Schnell, E., Chetkovich, D. M., Nicoll, R. A., \& Bredt, D. S. (2000). Psd-95 Involvement in Maturation of Excitatory Synapses. Science, 290, 1364-1368.

Garthe, A., Behr, J., \& Kempermann, G. (2009). Adult-Generated Hippocampal Neurons Allow the Flexible Use of Spatially Precise Learning Strategies. PLoS ONE, 4, e5464. http://dx.doi.org/10.1371/journal.pone.0005464

Hess, H. A., Roper, J. C., Grill, S. W., \& Koelle, M. R. (2004). Rgs-7 Completes a Receptor-Independent Heterotrimeric G Protein Cycle to Asymmetrically Regulate Mitotic Spindle Positioning in C. elegans. Cell, 119, 209-218. http://dx.doi.org/10.1016/j.cell.2004.09.025

Hubackova, S., \& Semradova, I. (2014). Research Study on Motivation in Adult Education. Procedia-Social and Behavioral Sciences, 159, 396-400. http://dx.doi.org/10.1016/j.sbspro.2014.12.395

Hurwitz, S. (1996). Homeostatic Control of Plasma Calcium Concentration. Critical Reviews in Biochemistry and Molecular Biology, 31, 41-100. http://dx.doi.org/10.3109/10409239609110575

Jean-Baptiste, G., Yang, Z., \& Greenwood, M. T. (2006). Regulatory Mechanisms Involved in Modulating RGS Function. Cellular and Molecular Life Sciences, 63, 1969-1985. http://dx.doi.org/10.1007/s00018-006-6066-y

Jo, J., Son, G. H., Winters, B. L., Kim, M. J., Whitcomb, D. J., Dickinson, B. A. et al. (2010). Muscarinic Receptors Induce LTD of NMDAR EPSCs via a Mechanism Involving Hippocalcin, AP2 and PSD-95. Nature Neuroscience, 13, $1216-1224$. http://dx.doi.org/10.1038/nn.2636

Kandel, E. R. (1978). A Cell-Biological Approach to Learning. Bethesda, MD: Society for Neuroscience.

Kemp, N., McQueen, J., Faulkes, S., \& Bashir, Z. I. (2000). Different Forms of LTD in the CA1 Region of the Hippocampus: Role of Age and Stimulus Protocol. European Journal of Neuroscience, 12, 360-366.

http://dx.doi.org/10.1046/j.1460-9568.2000.00903.x

Kovalchuk, Y., Hanse, E., Kafitz, K. W., \& Konnerth, A. (2002). Postsynaptic Induction of BDNF-Mediated Long-Term Potentiation. Science, 295, 1729-1734.

Leuner, B., \& Gould, E. (2010). Structural Plasticity and Hippocampal Function. Annual Review of Psychology, 61, $111-140$. http://dx.doi.org/10.1146/annurev.psych.093008.100359

Malenka, R. C., \& Bear, M. F. (2004). LTP and LTD: An Embarrassment of Riches. Neuron, 44, 5-21. http://dx.doi.org/10.1016/j.neuron.2004.09.012

Martin, S. J., Grimwood, P. D., \& Morris, R. G. (2000). Synaptic Plasticity and Memory: An Evaluation of the Hypothesis. Annual Review of Neuroscience, 23, 649-711. http://dx.doi.org/10.1146/annurev.neuro.23.1.649

Morris, R. G., Garrud, P., Rawlins, J. N., \& O’Keefe, J. (1982). Place Navigation Impaired in Rats with Hippocampal Lesions. Nature, 297, 681-683.

http://www.ncbi.nlm.nih.gov/entrez/query.fcgi?cmd=Retrieve\&db=PubMed\&dopt=Citation\&list uids=7088155

Neves, G., Cooke, S. F., \& Bliss, T. V. (2008). Synaptic Plasticity, Memory and the Hippocampus: A Neural Network Approach to Causality. Nature Reviews Neuroscience, 9, 65-75. http://dx.doi.org/10.1038/nrn2303

O’Keefe, J., \& Dostrovsky, J. (1971). The Hippocampus as a Spatial Map. Preliminary Evidence from Unit Activity in the Freely-Moving Rat. Brain Research, 34, 171-175.

O’Keefe, J., \& Nadel, L. (1978). The Hippocampus as a Cognitive Map. Oxford: Oxford University Press.

Olate, J., \& Allende, J. E. (1991). Structure and Function of G Proteins. Pharmacology \& Therapeutics, 51, 403-419. http://dx.doi.org/10.1016/0163-7258(91)90068-w

Otmakhov, N., Khibnik, L., Otmakhova, N., Carpenter, S., Riahi, S., Asrican, B., \& Lisman, J. (2004). Forskolin-Induced 
LTP in the CA1 Hippocampal Region Is NMDA Receptor Dependent. Journal of Neurophysiology, 91, 1955-1962. http://dx.doi.org/10.1152/jn.00941.2003

Paixao, S., \& Klein, R. (2010). Neuron-Astrocyte Communication and Synaptic Plasticity. Current Opinion in Neurobiology, 20, 466-473. http://dx.doi.org/10.1016/j.conb.2010.04.008

Pounds, J. G. (1984). Effect of Lead Intoxication on Calcium Homeostasis and Calcium-Mediated Cell Function: A Review. Neurotoxicology, 5, 295-331.

http://www.ncbi.nlm.nih.gov/entrez/query.fcgi?cmd=Retrieve\&db=PubMed\&dopt=Citation\&list_uids=6151637

Raymond, C. R. (2007). LTP Forms 1, 2 and 3: Different Mechanisms for the "Long” in Long-Term Potentiation. Trends in Neurosciences, 30, 167-175. http://dx.doi.org/10.1016/j.tins.2007.01.007

Ron, D., \& Jurd, R. (2005). The “Ups and Downs” of Signaling Cascades in Addiction. Science Signaling, 2005 , re14. http://dx.doi.org/10.1126/stke.3092005re14

Rosenmund, C., \& Stevens, C. F. (1996). Definition of the Readily Releasable Pool of Vesicles at Hippocampal Synapses. Neuron, 16, 1197-1207.

http://www.ncbi.nlm.nih.gov/entrez/query.fcgi?cmd=Retrieve\&db=PubMed\&dopt=Citation\&list_uids=8663996 http://dx.doi.org/10.1016/S0896-6273(00)80146-4

Saura-Llamas, J., Saturno Hernández, P. J., \& Romero Sánchez, E. (2006). Modelos formativos que pueden utilizar los tutores para formar residentes. FMC-Formación Médica Continuada en Atención Primaria, 13, 435-446. http://dx.doi.org/10.1016/S1134-2072(06)71354-8

Sehgal, M., Song, C., Ehlers, V. L., \& Moyer Jr., J. R. (2013). Learning to Learn-Intrinsic Plasticity as a Metaplasticity Mechanism for Memory Formation. Neurobiology of Learning and Memory, 105, 186-199. http://dx.doi.org/10.1016/j.nlm.2013.07.008

Shichida, Y., \& Morizumi, T. (2007). Mechanism of G-Protein Activation by Rhodopsin. Photochemistry and Photobiology, 83, 70-75.

Spencer, J. P. (2008). Food for Thought: The Role of Dietary Flavonoids in Enhancing Human Memory, Learning and Neuro-Cognitive Performance. Proceedings of the Nutrition Society, 67, 238-252. http://dx.doi.org/10.1017/S0029665108007088

Stewart, A. F. (1985). Calcium Metabolism without Anguish. Understanding the Body’s Homeostatic "Black Box”. Postgraduate Medicine, 77, 283-294.

http://www.ncbi.nlm.nih.gov/entrez/query.fcgi?cmd=Retrieve\&db=PubMed\&dopt=Citation\&list_uids=3966061

Sutherland, R. J., Kolb, B., \& Whishaw, I. Q. (1982). Spatial Mapping: Definitive Disruption by Hippocampal or Medial Frontal Cortical Damage in the Rat. Neuroscience Letters, 31, 271-276. http://www.ncbi.nlm.nih.gov/entrez/query.fcgi?cmd=Retrieve\&db=PubMed\&dopt=Citation\&list_uids=7133562 http://dx.doi.org/10.1016/0304-3940(82)90032-5

Tilakaratne, N., \& Sexton, P. M. (2005). G-Protein-Coupled Receptor-Protein Interactions: Basis for New Concepts on Receptor Structure and Function. Clinical and Experimental Pharmacology and Physiology, 32, 979-987. http://dx.doi.org/10.1111/j.1440-1681.2005.04295.x

Trifaro, J., Rose, S. D., Lejen, T., \& Elzagallaai, A. (2000). Two Pathways Control Chromaffin Cell Cortical F-Actin Dynamics during Exocytosis. Biochimie, 82, 339-352. http://dx.doi.org/10.1016/S0300-9084(00)00193-0

Ventura, R., \& Harris, K. M. (1999). Three-Dimensional Relationships between Hippocampal Synapses and Astrocytes. Journal of Neuroscience, 19, 6897-6906.

http://www.ncbi.nlm.nih.gov/entrez/query.fcgi?cmd=Retrieve\&db=PubMed\&dopt=Citation\&list_uids=10436047

Warner, D. R., \& Weinstein, L. S. (1999). A Mutation in the Heterotrimeric Stimulatory Guanine Nucleotide Binding Protein Alpha-Subunit with Impaired Receptor-Mediated Activation Because of Elevated GTPase Activity. Proceedings of the National Academy of Sciences of the United States of America, 96, 4268-4272. http://www.ncbi.nlm.nih.gov/entrez/query.fcgi?cmd=Retrieve\&db=PubMed\&dopt=Citation\&list_uids=10200251 http://dx.doi.org/10.1073/pnas.96.8.4268

Wayman, G. A., Lee, Y. S., Tokumitsu, H., Silva, A. J., \& Soderling, T. R. (2008). Calmodulin-Kinases: Modulators of Neuronal Development and Plasticity. Neuron, 59, 914-931. http://dx.doi.org/10.1016/j.neuron.2008.08.021

Whitlock, J. R., Heynen, A. J., Shuler, M. G., \& Bear, M. F. (2006). Learning Induces Long-Term Potentiation in the Hippocampus. Science, 313, 1093-1097.

Yang, S., Megill, A., Ardiles, A. O., Ransom, S., Tran, T., Koh, M. T. et al. (2013). Integrity of mGluR-LTD in the Associative/Commissural Inputs to CA3 Correlates with Successful Aging in Rats. Journal of Neuroscience, 33, 12670-12678. http://dx.doi.org/10.1523/JNEUROSCI.1086-13.2013

Yi, T. M., Kitano, H., \& Simon, M. I. (2003). A Quantitative Characterization of the Yeast Heterotrimeric G Protein Cycle. 
Proceedings of the National Academy of Sciences of the United States of America, 100, 10764-10769. http://dx.doi.org/10.1073/pnas.1834247100

Ziemann, U., \& Siebner, H. R. (2008). Modifying Motor Learning through Gating and Homeostatic Metaplasticity. Brain Stimulation, 1, 60-66. http://dx.doi.org/10.1016/j.brs.2007.08.003 